\title{
Design optimization of improved cooking stove
}

\author{
S Prajapati ${ }^{{ }^{*}}$, B Rijal $^{1}$, M Rijal $^{1}$, B Baral $^{2}$ \\ ${ }^{1}$ School of Engineering, Kathmandu University, Dhulikhel, Nepal \\ ${ }^{2}$ Technical Training Center, Kathmandu University, Dhulikhel, Nepal
}

\begin{abstract}
Improved cooking stove (ICS) has provided the emerging opportunities, especially in the developing nations, considering the fact that it is more efficient and environment friendly than conventional cooking stoves. The paper briefly discusses about the design optimization of ICS. Current models are designed predominantly based on maximum energy conversion rather than coupling it with the original habits of users. There are various factors to be considered during the design of the cooking stove. The optimum design has the maximum efficiency resulting in low carbon emission, low kitchen indoor pollution, low fuel wood consumption and finally conserves the environment.
\end{abstract}

Key words: Efficiency, Fuels, Improved cooking stoves, Optimization

\section{Introduction}

During the last decade concept of the ICS has been hugely popular among the traditional stove users since it is the upgraded version of the rudimentary cooking stoves. The most commonly used fuels such as wood, crop residue, dung and their derivatives meet the cooking and heating energy requirements of nearly half of the world's population (Lionberg, 2011). Improved cooking stove seems to be introduced in Nepal with the aim of reducing high infant mortality rate caused by exposure of women to indoor air pollution from inefficient fuelwood fed traditional cooking stove. The organizations like Central Renewable Energy Fund (CREP), Alternative Energy Promotion Center (AEPC) and Renewable Nepal have been promoting the use of IC S in Nepal (Fig. 1). Around 650,000 ICS have been installed in 12 years under AEPC's national ICS program, including some 7,500 metallic ICS. Recent annual rate of installation is 80,000 to 100,000 households (Rai, 2011). The use of the IC S has reduced the fuel wood consumption rate, thereby reducing deforestation, maintaining ecosystem and providing sustainable income for people of those parts. IC $\mathrm{S}$ is a remarkable engineering design, focusing on optimal utilization of available resources for maximum effect. ICS was developed to minimize worse-off effects, if any, while optimizing the better-off side. According to Water and Energy Commission Secretariat, $86.5 \%$ of household uses firewood as the primary source of fuel. So improvement in design of cooking stoves can really have a significant impact on the fuel wood consumption and reduce the rate of deforestation in Nepal. Efficiency of traditional cooking stoves is only $3-15 \%$ whereas that of IC S efficiency ranges from 15-30\% ( $\mathrm{R}$ ai, 2011).

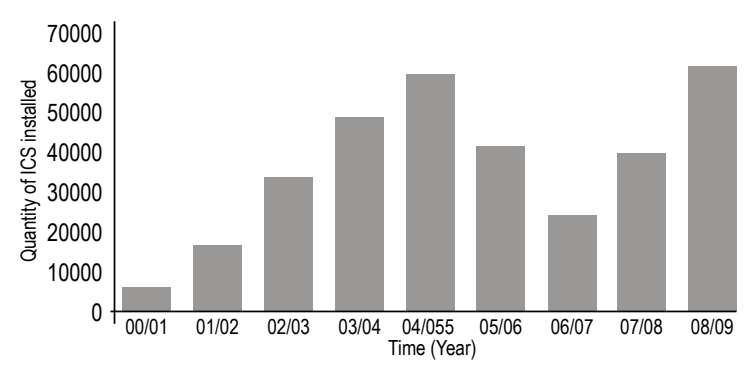

Fig. 1 Trend of installation of improved cooking stoves (Water and Energy Comission Secretariat, 2010)

AEPC's new framework National Rural and Renewable Energy Program (NRREP) has allocated a committed budget of US\$184 million for 5 years which targets to install at least 475,000 ICS within that period. Nepal has recently set an ambitious goal of "Clean Cooking Solutions for All by 2017 (CCS4ALL)" which mainly includes three categories i.e. ICS, biogas and solar cooker (Rai, 2011).

\section{Materials and Methods}

Optimum design is always prefer red for any system which is not so simple to achieve in case of ICS. Unlike steady state condition, the variables used in the design of IC S is rather transient and random that adds more complexity for analysis. However, simplification is done in such a way that the analysis only focuses on the dominating parameters of the system.

Efficiency is affected by a number of parameters which are categorized into two; internal and external. Internal variables 
include grate to pot height, fuel feed rate, stove diameter (Fig. 2) whereas the variables like type of fuel, location of kitchen and stove, and ambient conditions are external. But in this research, the influence of grate to pot height, fuel feed rate and types of fuel used is studied. According to 10 design principles, there are several standard things to be considered for the design of cooking stoves like constant cross section throughout the stove, proper insulation; optimum fuel feed rate, necessar y natural draft, etc. (Dr. Mark Bryden).

Higher the efficiency of stove better is the environment friendliness. Efficiency of the stove is basically the amount of heat absorbed by water for vaporization to amount of heat generated during combustion of fuel (Equation 1).

$$
\eta=\frac{\text { Amount of heat absorbed by the water for vapourization }}{\text { Amount of heat generated during combustion of fuel }}
$$

Heat is transfer red mainly via radiation in stoves, but conduction, convection and absorption are accounted as loss (Chomcharn, 2010). Primarily, there are two types of efficiencies- combustion efficiency and heat transfer efficiency, the product of which is the overall efficiency (Equation 2).

$$
\eta_{\text {overall }}=\eta_{\text {beat transfer }} \times \eta_{\text {combustion }}
$$

Where heat transfer efficiency according to Chomcharn is: Where,

$$
\text { E fficiency }(\eta)=\frac{Q_{\text {sensible }}+m_{v} b_{f g}\left(t_{2}-t_{1}\right)}{a A_{g} \Delta H t_{2}}
$$

$Q_{\text {sensible }}=$ heat content of remaining water

$m_{v}=$ rate of vaporization of water

$h_{f g}=$ latent heat of vaporization

$t_{2}-t_{1}=$ difference between time duration

$a=$ constant

$A_{g}=$ grate hole area

$\Delta H=$ net heat liberated from one $\mathrm{kg}$ coal (fuel)

After further derivation equation 1 becomes:

$$
\begin{aligned}
\operatorname{Efficiency}(\eta)= & a_{1}\left(\frac{t_{2}-t_{1}}{H t_{2}}\right)-a_{2} G\left(\frac{t_{2}-t_{1}}{A_{2} H t_{2}}\right)-a_{3} m_{s}\left(\frac{t_{2}-t_{1}}{A_{2} H t_{2}}\right) \\
& -a_{4} \frac{m_{s}}{D^{2}}\left(\frac{t_{2}-t_{1}}{A_{2} H t_{2}}\right)
\end{aligned}
$$

Where, $a_{1=\mathrm{y}}, \quad a_{2}=\frac{y \beta}{a \Delta H}, \quad a_{3}=\frac{y \epsilon}{a \Delta H}, \quad a_{4}=\frac{y \delta}{a \Delta H}$

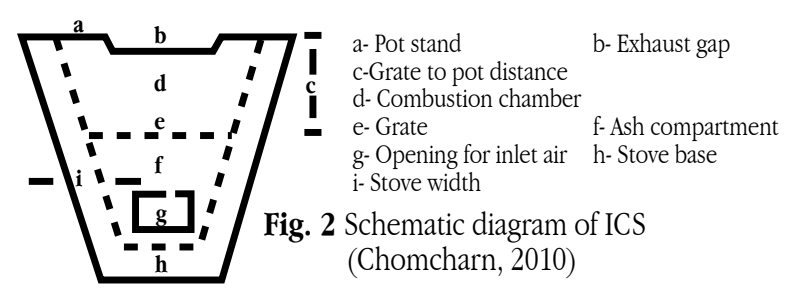

\section{Results and Discussion Internal parameters \\ Grate to pot beight}

As shown in equation 4 , the heat transfer efficiency of the stove is in inverse relation to grate to height gap i.e. higher the height of the stove, lesser the efficiency, thus time taken to boil water increases and vice versa. This effect can be explained with the help of view factor (Chomcharn, 2010). As $\mathrm{H}$ increase the view factor decreases, causing the reduction of heat transfer through radiation since heat is being intercepted by the pot from the flame; which means most of the heat is lost, when the charcoal is ver y far from the combustion zone, this limits the amount of heat being supplied and increases the time to boil (Chomcharn, 2010).

Time to boil is always minimum at optimum height (point 0) (Fig. 3). If this height cannot be achieved due to various constrains, the portion of graph towards the right is more preferable. For example: efficiency of $30 \%$ is achieved in both 8 and 11 grate to pot height. The latter one is prefered despite having same heat transfer efficiency as it produces comparatively lesser emission. This reduction of emission is due to higher residence time of flue gas, which proves it to be more environmental friendly. Residence time is the interval between entry and exit of the stove. When the height is greater, the smoke remains in the stove for longer period that further increases the possibility of extracting ener gy from the smoke containing small amount of unbur nt fuel and consequently reduces the emission.

As heat transfer efficiency and height are inversely proportional, the stove should have ver y high efficiency for minimum height. However, it is not practical since combustion efficiency limits the overall maximum efficiency of the stove (Equation 2). This means that despite of increase in heat transfer efficiency, there should also be an optimum height, as overall efficiency is synergetic effect of both the efficiencies (Fig. 4).

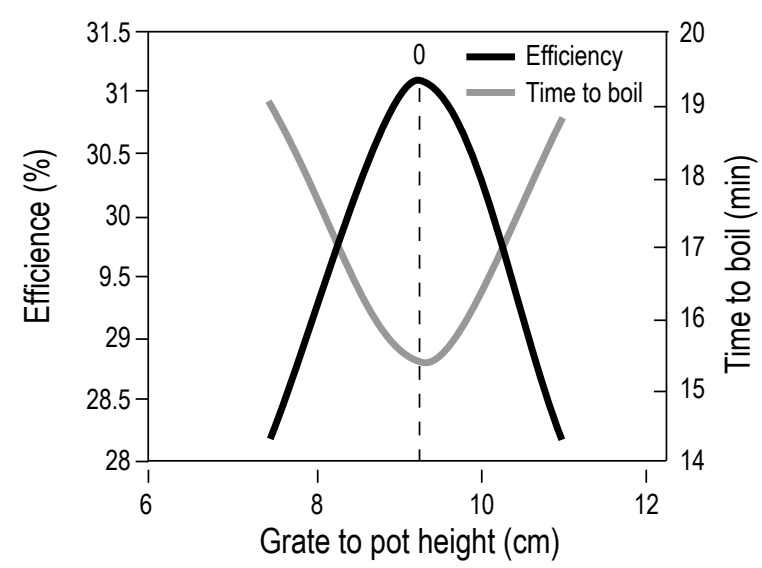

Fig. 3 Height versus efficiency (Chomcharn, 2010)

\section{TU-CDES}




\section{Fuel feed rate}

The fuel feed rate is directly related to the efficiency of the stove (Fig. 5). The efficiency of the stove decreases with increasing fuel feed rate and decreasing time to boil. This may be due to the clogged up combustion chamber (Chomcharn, 2010). Therefore, for better fuel combustion the limiting factor should always be fuel not the air. From the point of view of indoor pollution, excess air is always preferable, whereas increase in fuel feed rate beyond optimum level limits the air, which in not desirable.

\section{External parameter}

\section{Types of fuel}

Varieties of fuels are used in Nepal for domestic purpose (Fig. 6). It shows that the fuel wood is most extensively used for household purposes. There are various options for household fueling (F ig. 7), which shows hierarchical arrangement of different available sources of ener gy in increasing order of calorific value and cost of fuel. In context of Nepal, fuel wood is the best option among other fuels, as wood lies in a place which is better in ter ms of energy content (calorific value), cost and availability. Therefore, it is popular among both consumers and researchers as a renewable fuel source.
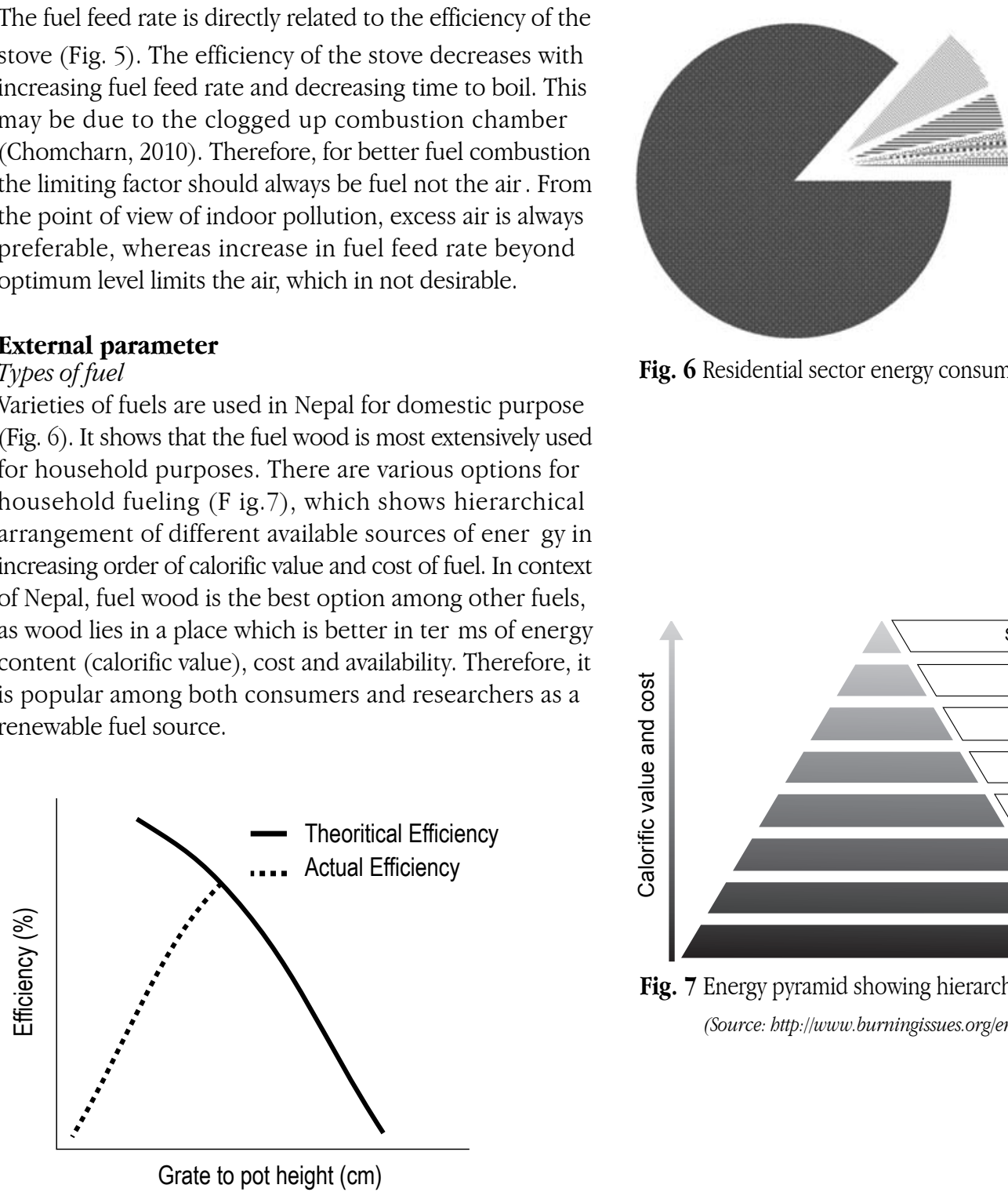

a fuel wood $(86.5 \%)$

is animal dung(6.5\%)

$\equiv$ agricultural residue(3.7\%)

= solar $(0 \%)$

micro-hydro(0\%)

biogas $(0.7 \%)$

nother petroleum( $0 \%)$

o LPG(0.9\%)

kerosene $(0.6 \%)$

\#\# electricity $(1 \%)$

an $\operatorname{coal}(0 \%)$

Fig. 6 Residential sector energy consumption (Rai, 2011)

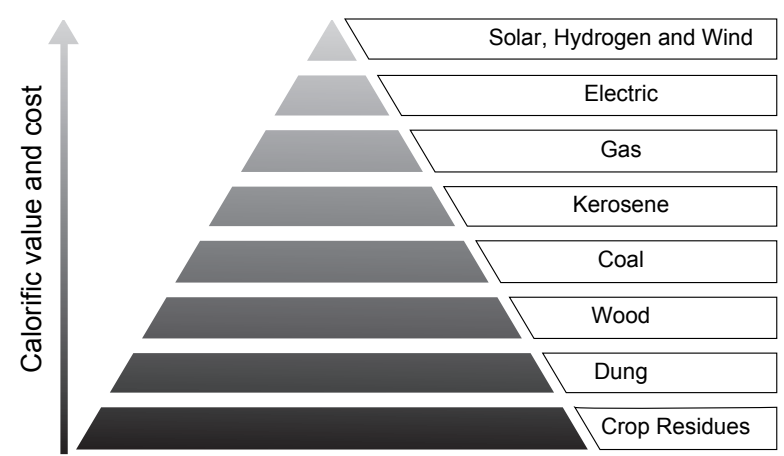

Fig. 7 Energy pyramid showing hierarchial order of fuel types (Source: bttp://www.burningissues.org/energy-ladder.htm)

Fig.4 Nature of theoritical and actual efficiency
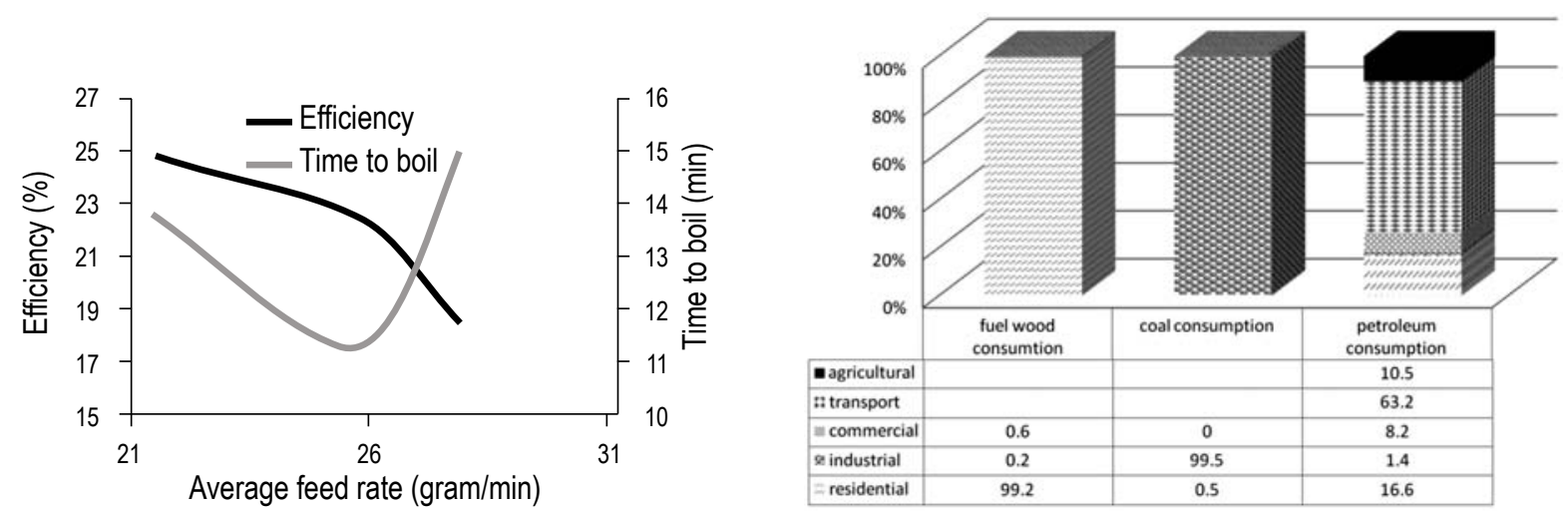

Fig. 5 Fuel feed rate versus efficiency (Chomcharn, 2010) 


\section{Conclusion}

Whether it be biogas or improved cooking stoves, these are the most successful bio-energy technology used all over the world. ICS is an emerging product and has great potential to improve the general cooking practices that is being used for a long time. Since cooking stoves are used by more than half of the population, not only just in Nepal but also in the whole world, the efficient cooking stoves significantly reduces the rate of fuel consumption and its adverse effect. Thus, ICS is an environment friendly technology.

The methodology behind optimization is to find the dominating parameters of the system. In stoves, the dominating variables are grate-to-pot height, fuel feed rate, diameter, type and quality of fuel used etc. Design optimization of few factors has been reflected. For efficient stoves, the optimum height is always preferred. The common cooking practice should also be changed for the better environment friendly stoves i.e. the feed rate should be controlled because beyond the optimum feed rate lavel, the efficiency decreases.

\section{References}

Bryden, M., Still, D,, Scott, P., Hoffa, G., Ogle, D., Ballis, R., \& Goyer, K (Undated). Design Principles for Wood Burning Cook stoves, A Provecho Research Center Shell Foundation Partnership for Clean Indoor Air, USA.

Chomcharn, A. (2010). Improved Biomass cooking Stove for Housebold Use. National Energy Administration USAID, Thailand.

Lionberg, A. (2011). Fine Resolution CFD Simulation Approach for biomass cooking stove. Colorado State University, Colorado, USA.

Rai, S. (2013). Improved Cookstoves \& Fuel Markets in Nepal: Opportunities for All. SNV, Kathmandu, Nepal.

WECS (2010). Energy Sector Synopsis Report 2010. Water and Energy Commission Secretariat (WECS), Kathmandu, Nepal. 